\title{
Synthesis and gas sensing properties of $\mathrm{ZnO}$ single crystal flakes
}

\author{
Ying Liu, ${ }^{a}$ Jian Dong, ${ }^{a}$ Peter J. Hesketh ${ }^{b}$ and Meilin Liu*a \\ Received 28th February 2005, Accepted 31st March 2005 \\ First published as an Advance Article on the web 11th April 2005 \\ DOI: 10.1039/b502974k
}

We report a new two-dimensional structure, $\mathrm{ZnO}$ single crystal flakes, synthesized using a simple combustion CVD process. The flakes grew upward from the $\mathrm{Si}$ substrate. The as-grown $\mathrm{ZnO}$ flakes were less than $200 \mathrm{~nm}$ thick and 10-20 $\mu \mathrm{m}$ wide. Unlike most 1-D ZnO structures with [0001] growth direction, $\mathrm{ZnO}$ flakes grow along $<10 \overline{1} 0>$ directions. A gas sensor based on a $200 \mathrm{~nm}$ thick $\mathrm{ZnO}$ flake exhibited fast response-recovery and high sensitivity to ethanol vapor. These as-synthesized single crystal $\mathrm{ZnO}$ flakes could have important technological applications.

\section{Introduction}

Because of its unique properties (e.g., wide direct bandgap of $E_{\mathrm{g}}=3.2 \mathrm{eV}$, piezoelectric and semiconducting behavior), $\mathrm{ZnO}$ has found numerous applications, including UV light-emitters, solar cells, transparent high power electronics, piezoelectric transducers, and gas sensors. As one of the earliest discovered and well-established gas sensing oxides, ${ }^{1} \mathrm{ZnO}$ has been extensively studied for the detection of inflammable or toxic gases such as $\mathrm{H}_{2}, \mathrm{C}_{2} \mathrm{H}_{5} \mathrm{OH}, \mathrm{CO}$ and $\mathrm{NO}_{x} \cdot{ }^{2-5}$ It has been recognized that gas sensors based on nanostructured fibrous $\mathrm{ZnO}$ exhibited greater sensitivities and faster response than those based on their bulk counterparts. ${ }^{6-8}$ Similarly, a single $\mathrm{ZnO}$ nanowire photodetector showed several orders of magnitude increase in conductance upon exposure to UV light. Development in integrated and smart systems requires a direct integratation of sensor elements or sensor arrays with signal processing unit within a single chip to achieve higher sensitivity and selectivity. Thus miniaturization of active sensing elements is essential. ${ }^{9}$ To date, bulk single crystals, 1-D nanostructures, and 0-D nanoparticles of $\mathrm{ZnO}$ have been synthesized and tested for various applications. It is believed that the high surface to volume ratio renders these structures spectacular properties. In this paper, we report a new 2-D $\mathrm{ZnO}$ structure, single crystal $\mathrm{ZnO}$ flakes of $50 \mathrm{~nm}$ to $1 \mu \mathrm{m}$ thick, synthesized using a combustion chemical vapor deposition (CVD) process. Further, a tiny gas sensor has been fabricated by placing a fraction of a $\mathrm{ZnO}$ flake on interdigitated electrodes on a silicon substrate. The sensor demonstrated high signal to noise ratio and fast responserecovery to ethanol vapor.

$\mathrm{ZnO}$ has a hexagonal (wurtzite) crystal structure with $a=$ $3.25 \AA$ and $c=5.12 \AA$. Each $\mathrm{Zn}$ atom is tetrahedrally coordinated to four $\mathrm{O}$ atoms. $\mathrm{Zn}$ and $\mathrm{O}$ atoms alternately occupy crystallographic planes, forming layered structure. Therefore, anisotropic growth is expected in several crystallographic directions, including $<2 \overline{1} \overline{1} 0>,<10 \overline{1} 0>$, and $<0001>$. One-dimensional $\mathrm{ZnO}$ nanostructures such as nanowires, nanobelts, and nanorings have been reported in literature. ${ }^{10-13}$ Hexagonal $\mathrm{ZnO}$ single crystals with $\{0001\}$ exposure surfaces and $<2 \overline{1} \overline{1} 0\rangle,<10 \overline{1} 0>$ growth directions, are energetically favored. Large, 2-D structures could form in this way.

\section{Experimental}

$\mathrm{ZnO}$ single crystal flakes were synthesized using a combustion vapor condensation process as described elsewhere. ${ }^{14-17}$ The experimental apparatus for combustion CVD is schematically illustrated in Fig. 1. Zinc nitrate (from Aldrich) is dissolved in ethanol with a concentration of $0.005 \mathrm{M}$. The solution is then delivered to an atomizer where a fine mist of solution is generated and combusted with the assistance of a small methane flame. Si slices $(1 \mathrm{~cm} \times 1 \mathrm{~cm})$ cut from a $\mathrm{Si}$ wafer were used as substrates. A type $\mathrm{K}$ thermocouple is placed in the vicinity of the substrate surface to monitor deposition temperature. Depositions were performed at $1100{ }^{\circ} \mathrm{C}$ for $30 \mathrm{~min}$. The as-grown $\mathrm{ZnO}$ flakes were characterized using a scanning electron microscope (SEM, LEO 1530 ThermallyAssisted FEG) with an energy dispersive spectroscopy (EDS) attachment, a transmission electron microscope (TEM, JEOL 100C), and an X-ray diffractometer (XRD, Phillips PW-1800).

The as-synthesized $\mathrm{ZnO}$ flakes were scratched into an ethanol bath, ultrasonically dispersed and broken into smaller pieces. A drop of the suspension was transported to patterned Pt electrodes and dried naturally. The dropping process was repeated until a single $\mathrm{ZnO}$ flake could be observed bridging

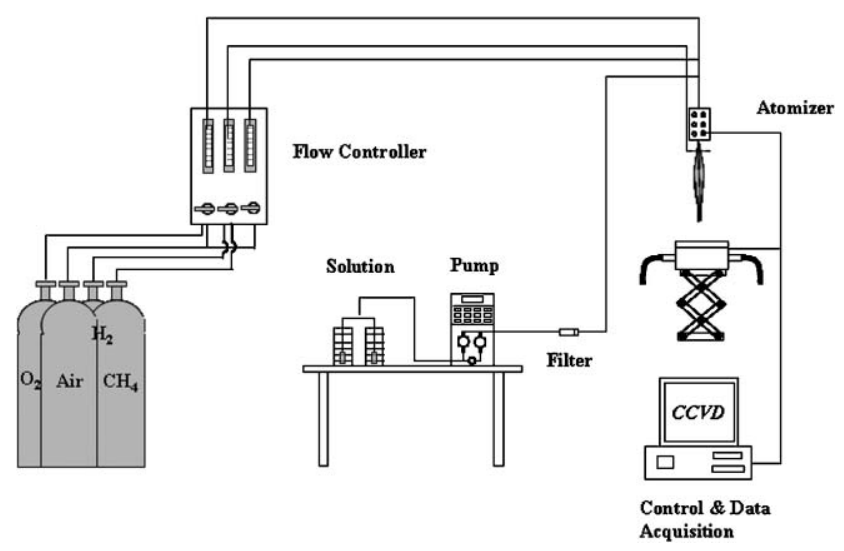

Fig. 1 A schematic of combustion CVD process. 
two electrodes. The sensor was tested in ethanol vapor (300 and $500 \mathrm{ppm}$ balanced by air) at $400{ }^{\circ} \mathrm{C}$ at a gas flow rate of $100 \mathrm{sccm}$. The current flowing through the $\mathrm{ZnO}$ flake was measured using a Solartron 1255 Electrochemical Interface at an applied constant voltage of $100 \mathrm{mV}$.

\section{Results and discussion}

Shown in Fig. 2 are some typical morphologies of the assynthesized $\mathrm{ZnO}$ flakes. These $\mathrm{ZnO}$ flakes were randomly and fairly uniformly distributed on the substrate (Fig. 2a). An angular view (Fig. 2b) more clearly shows that $\mathrm{ZnO}$ flakes are oriented upward with respect to the underlying substrate. The higher magnification image (Fig. 2c) shows that each $\mathrm{ZnO}$ flake has a cactus-like shape with the maximum dimension of
15 to $20 \mu \mathrm{m}$ on the top and gradually narrowing down to the bottom. Fig. 2d shows a SEM micrograph of a single $\mathrm{ZnO}$ flake. The thickness of the $\mathrm{ZnO}$ flakes can be up to $1 \mu \mathrm{m}$ as shown in Fig. $2 \mathrm{~d}$ or as thin as 150 to $250 \mathrm{~nm}$ (Fig. 2e, 2f). The large surface appears to be very smooth while the peripheral surfaces are faceted, showing a hexagonal pattern. These features indicate each $\mathrm{ZnO}$ flake probably is a single crystal with $\{0001\}$ flat surface.

The composition of the as-synthesized product was analyzed by SEM/EDX. As shown in Fig. 3a, only $\mathrm{Zn}$ was detected. Typical XRD pattern shown in Fig. $3 b$ indicates that the product has wurtzite structure with cell constants of $a=3.25 \AA$ and $c=5.20 \AA$ (JCPDS card 03-0888).

These characteristics were further confirmed by TEM analysis. Shown in Fig. 4a is a TEM bright field image

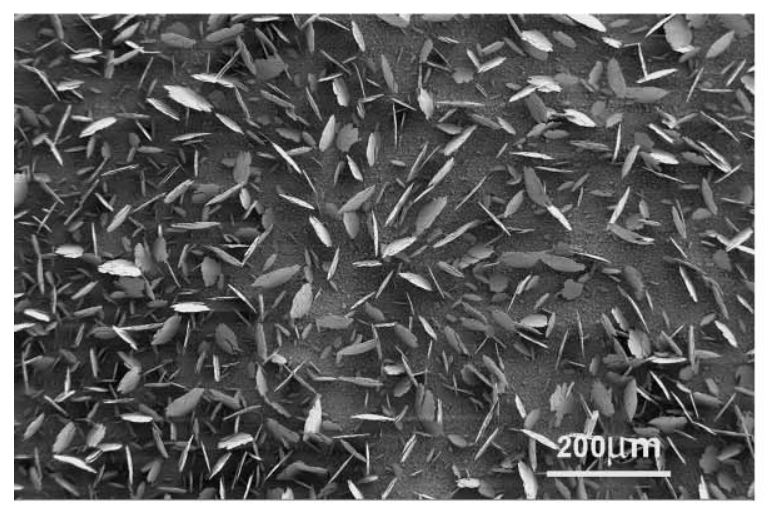

(a)

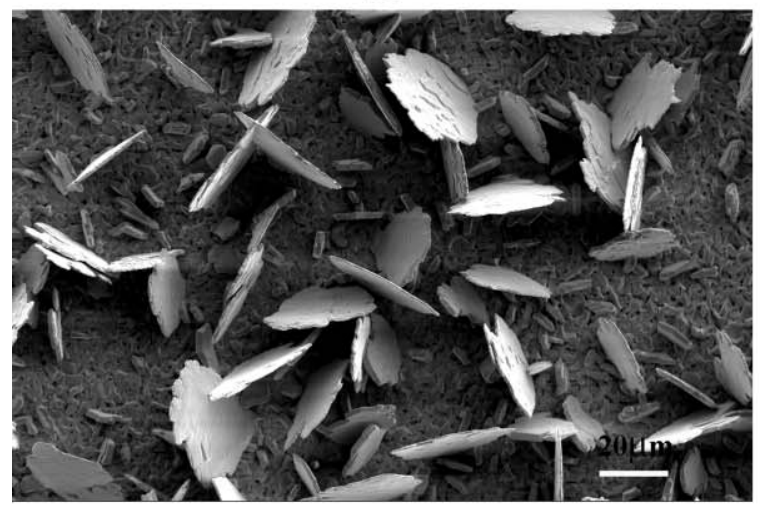

(c)

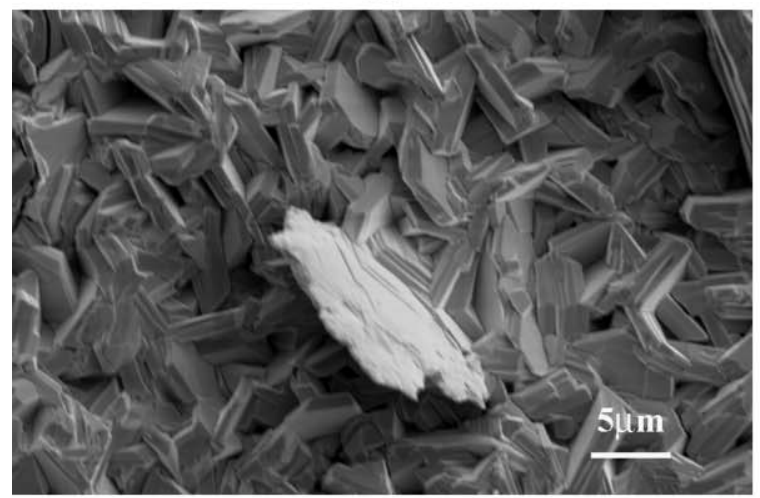

(e)

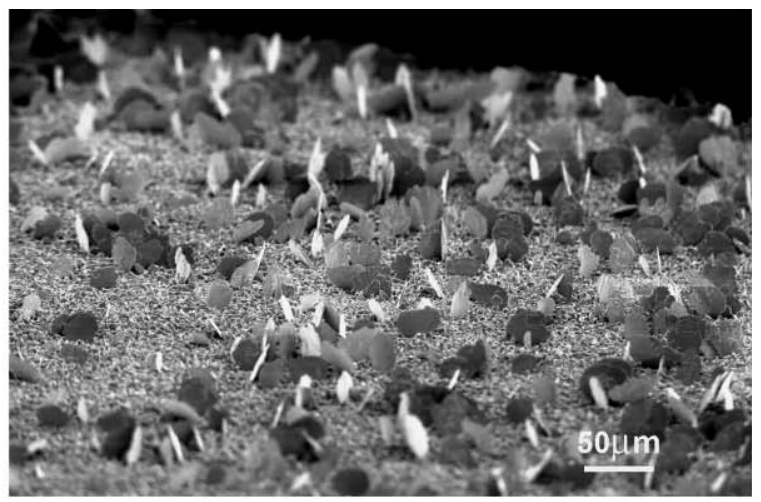

(b)

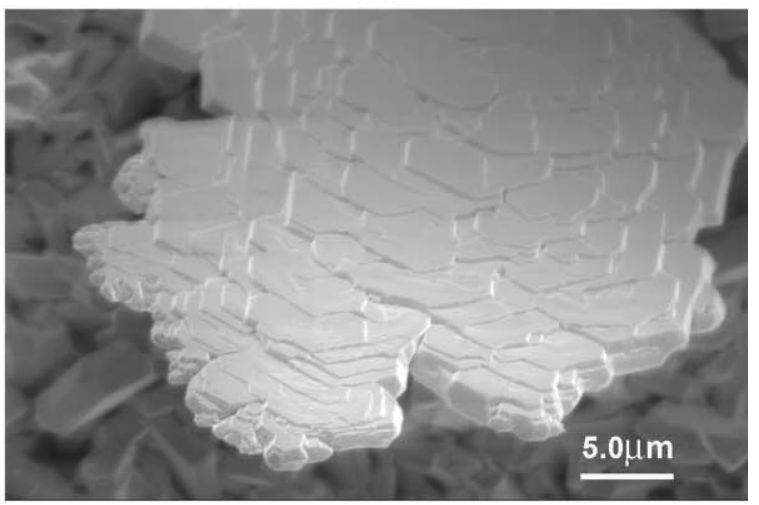

(d)

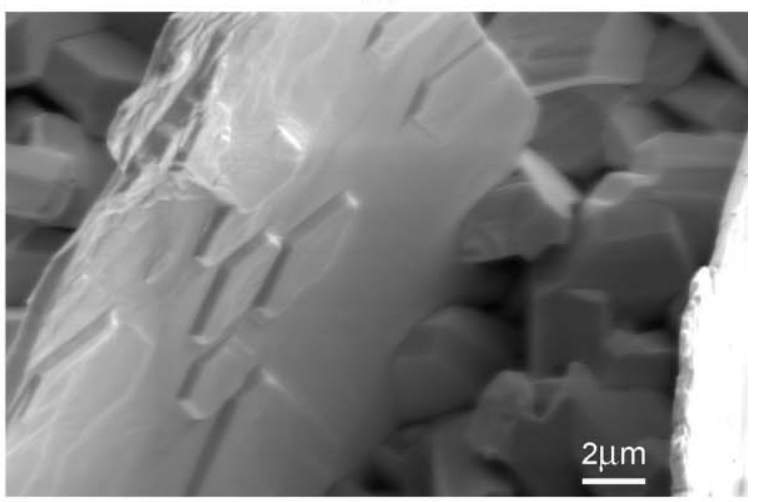

(f)

Fig. 2 SEM images of $\mathrm{ZnO}$ flakes synthesized at $1100{ }^{\circ} \mathrm{C}$ using a combustion CVD process. 


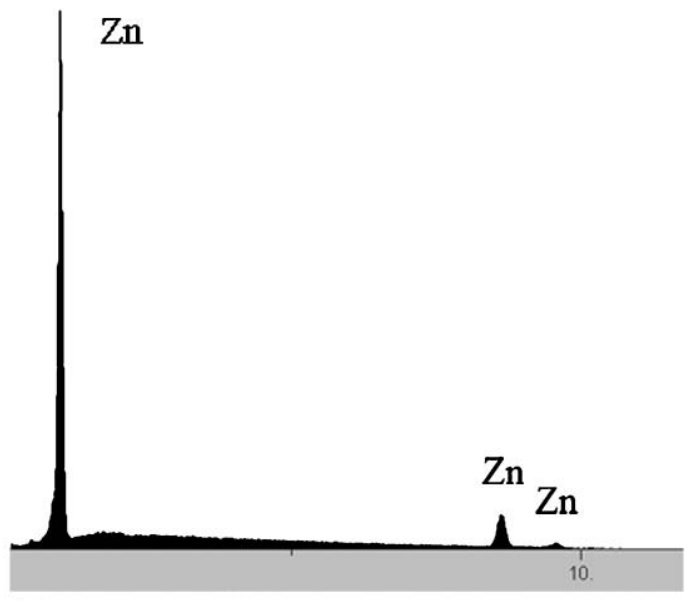

(a)

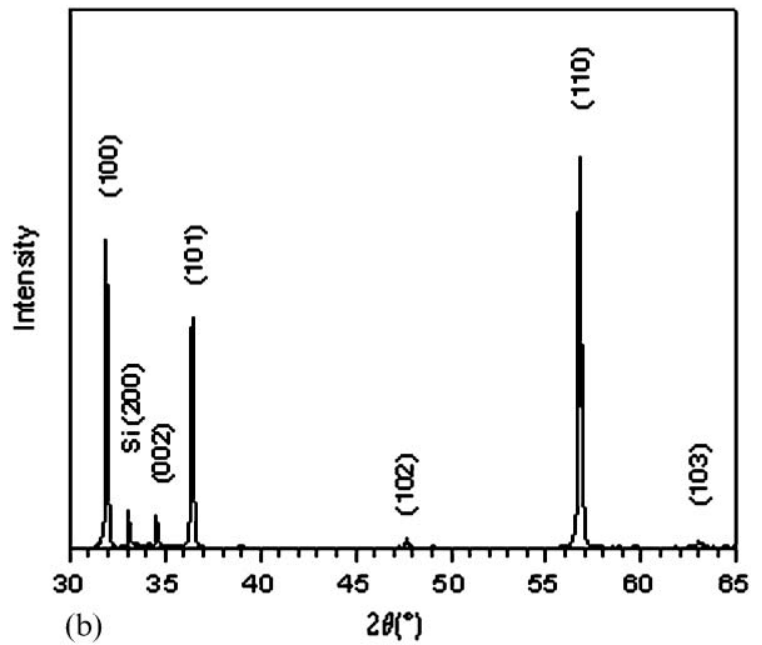

Fig. 3 (a) EDX analysis of the $\mathrm{ZnO}$ flakes, and (b) XRD spectra.

together with an inset showing the corresponding selected area electron diffraction (SAED) pattern, indicating that each $\mathrm{ZnO}$ flake is a single crystal with wurtzite structure. The peripheral facets intersecting one another at approximately $120{ }^{\circ} \mathrm{C}$ were identified as $\{10 \overline{1} 0\}$ planes. The corresponding zone axis was determined to be [0001].

As a wurtzite structure, $\mathrm{ZnO}$ typically has three fast growth directions, $<2 \overline{1} \overline{1} 0>,<10 \overline{1} 0>$, and $<0001>$, corresponding to three low energy crystallographic planes, $\{2 \overline{1} 10\},\{10 \overline{1} 0\}$, and $\{0001\}$ respectively. Preferential growth in a particular direction is under kinetic control of synthesis conditions. For $\mathrm{ZnO}$ wire or rod-like structures, the growth predominantly follows $<0001>$ orientation, independent of pre-introduced catalysts. ${ }^{10,11,18-20}$ In this case, lateral surface planes are sets of $\{2 \overline{1} \overline{1} 0\}$ or $\{10 \overline{1} 0\}$ planes, resulting in a hexagonal appearance. The growth direction of $\langle 2 \overline{1} \overline{1} 0\rangle$ was observed in $\mathrm{ZnO}$ nanobelts where $\{0001\}$ planes form the two larger peripheral surfaces. ${ }^{21}$ The other two $\{10 \overline{1} 0\}$ peripheral surfaces did not grow significantly. In our situation, except the dominating lateral $\{0001\}$ surfaces, all the fast growth fronts were covered by $\{10 \overline{1} 0\}$ facets as illustrated in Fig. $4 \mathrm{~b}$.

The growth mechanism for $\mathrm{ZnO}$ single crystal flakes is believed to be similar to the one found for $\mathrm{SnO}_{2}$ nanotube

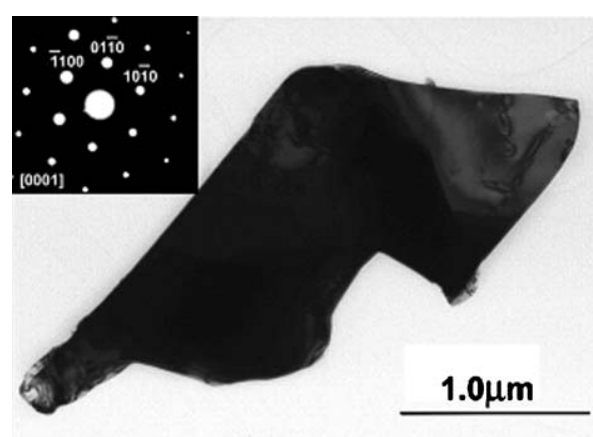

(a)

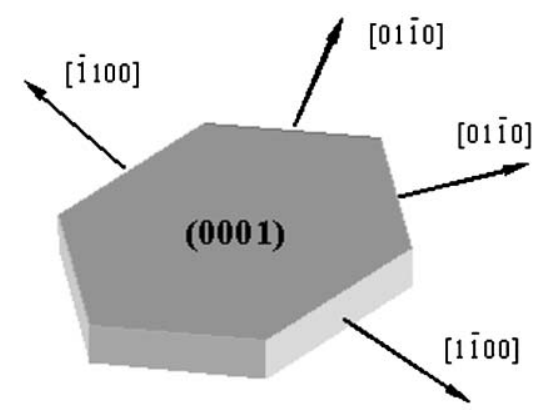

(b)

Fig. 4 (a) TEM image and the corresponding SAED pattern of a $\mathrm{ZnO}$ single crystal flake, and (b) a schematic showing the preferential growth orientation of $\mathrm{ZnO}$ flakes.

arrays synthesized using the same combustion CVD process. ${ }^{22}$ A simple direct vapor-solid (VS) conversion model can be applied to explain the growth of $\mathrm{ZnO}$ single crystal flakes. Initially, zinc nitrate precursor is decomposed and converted into $\mathrm{ZnO}$ vapor within the combustion flame. The resulting vapor species is then condensed on the relatively cold $\mathrm{Si}$ substrate, accumulating to a bulk layer. This stage continues for a relatively long period of time since there was no preferential growth of $\mathrm{ZnO}$ flakes observed under microscope even after $20 \mathrm{~min}$ of deposition. As condensation continues, the grains with energetically or kinetically favorable crystallographic planes will grow faster than the others. Once initiated, this preferential growth process will be accelerated since the top layer receives more $\mathrm{ZnO}$ vapor and also experiences higher temperature than the layer below. SEM images shown in Fig. 5 reveal different growth stages of $\mathrm{ZnO}$ flakes. Under these favorable growing conditions, $\mathrm{ZnO}$ single crystal flakes expand in two dimensions and gradually grow into cactus-like shape with wider top and narrower bottom. Although at a much smaller rate, $\mathrm{ZnO}$ vapor received at the root also contributes to the increase of the height. The same mechanism has been proposed to explain the growth of $\mathrm{ZnO}$ nanonails, which have large caps and very slim shafts. ${ }^{23}$ Close observation reveals that each $\mathrm{ZnO}$ flake consists of layered structures with each layer in the thickness of 50 to $250 \mathrm{~nm}$ (Fig. 2e, Fig. 5a, 5b). During deposition, some layers could grow much faster than others. The final $\mathrm{ZnO}$ flake can be very thin (Fig. 2e, 2f). It is interesting to note in Fig. 2f, isolated small hexagonal $\mathrm{ZnO}$ layers could nucleate and grow on the surface of a larger flake. Nucleation on $\{0001\}$ polar surfaces 


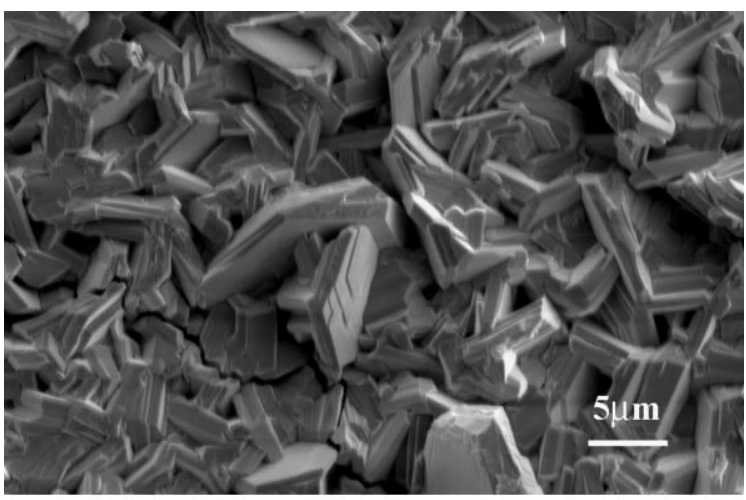

(a)

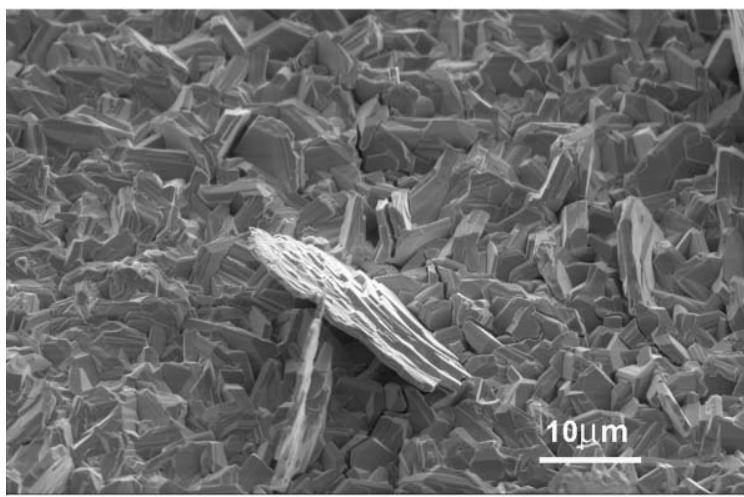

(b)

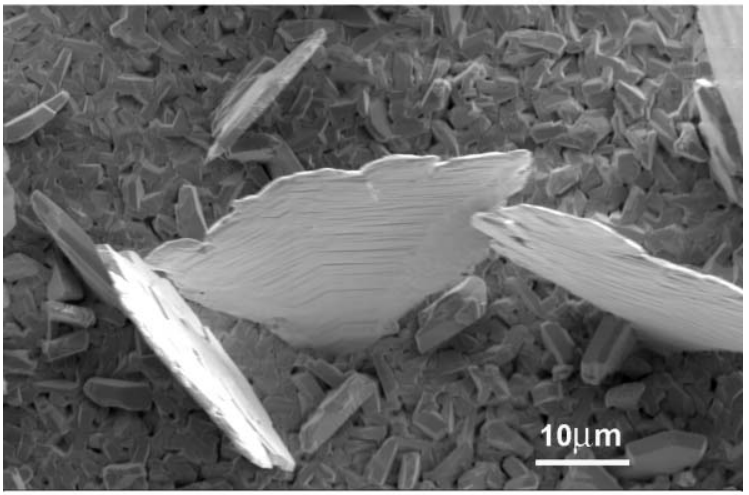

(c)

Fig. 5 SEM images of $\mathrm{ZnO}$ flakes taken at different stages of growth. Synthesis temperature was $1100{ }^{\circ} \mathrm{C}$.

could be initiated by introducing planar defects to the polar surfaces. ${ }^{24}$

The width/thickness ratio of each $\mathrm{ZnO}$ single crystal flake ranged from 25 to 100 . The large specific area of $\mathrm{ZnO}$ flakes would dramatically enhance the kinetics of electrochemical and catalytic processes. As a demonstration, a gas sensor was fabricated by placing a fraction of a $\mathrm{ZnO}$ flake onto interdigitated Pt electrodes, as shown in Fig. 6a. The thickness of the $\mathrm{ZnO}$ flake is about $200 \mathrm{~nm}$. The sensor was tested at $400{ }^{\circ} \mathrm{C}$ in ethanol vapor. The performance of the $\mathrm{ZnO}$ flake sensor is shown in Fig. 6b; the sensor responded quickly as the gas was switched from air to different concentration of ethanol vapor and recovered fully when the gas was switched back to air.

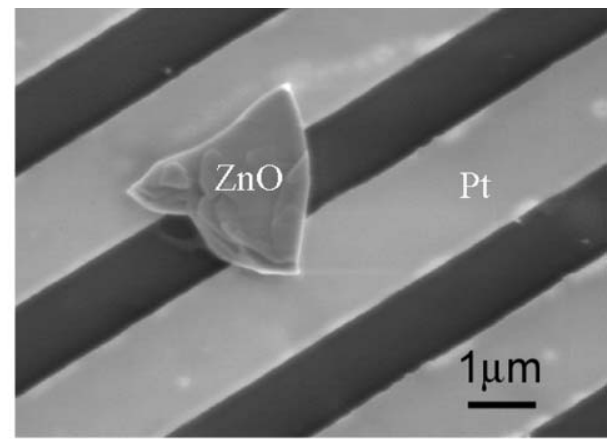

(a)

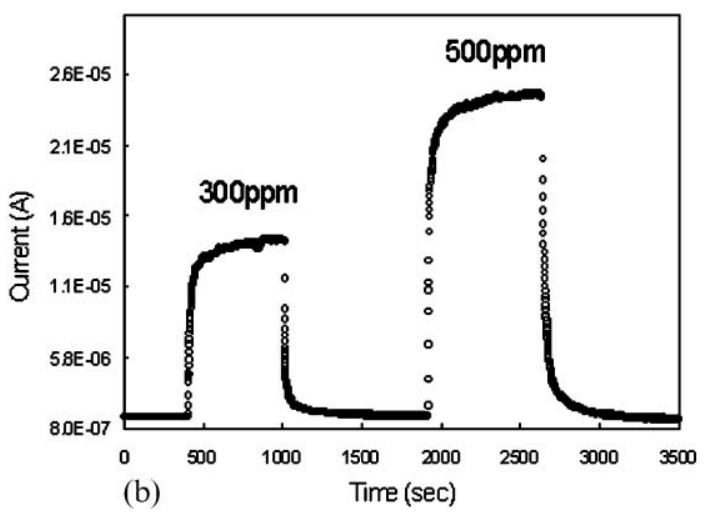

Fig. 6 A solid-state gas sensor based a single crystal $\mathrm{ZnO}$ flake. (a) SEM micrograph of the sensor consisting of a $\mathrm{ZnO}$ flake and $\mathrm{Pt}$ interdigitated electrodes, and (b) current variation with time under a constant voltage of $100 \mathrm{mV}$ as sample gas was switched from air to different concentrations of ethanol vapor at $400{ }^{\circ} \mathrm{C}$. Data were collected at one second intervals.

The response and recovery time is defined as the time needed to reach $90 \%$ of the full response $\left(R_{\mathrm{f}}-R_{0}\right)$, where $R_{\mathrm{f}}$ is the full-scale conductance when the sensor is in equilibrium with the ethanol vapor and $R_{0}$ is the baseline conductance when the sensor is in equilibrium with air. As shown in Fig. 6b, it took $62 \mathrm{~s}$ at $400{ }^{\circ} \mathrm{C}$ for the sensor to respond to ethanol vapor (reach $90 \%$ of its full response) and approximately the same amount of time to recover. The ratio of $\left(R_{\mathrm{f}}-R_{0}\right) / R_{0}$ was 7.8 and 14.3 when the atmosphere was switched from air to 300 and 500 ppm ethanol vapor, respectively.

The gas sensing behavior of a semiconducting oxide can be attributed to both surface and bulk interactions, depending on grain size or film thickness. If grain size or film thickness is much larger than the Debye length $\lambda_{\mathrm{D}}$ of the material, the bulk interactions will dominate the sensor response. On the other hand, if grain size or film thickness is smaller than or in the same order of magnitude as $\lambda_{\mathrm{D}}$, surface interactions will dominate the sensor behavior. ${ }^{25,26}$ The large surface to volume ratio and small size of the $\mathrm{ZnO}$ flake sample suggest that ethanol-ZnO interactions on the surface may play an important role.

The interactions between ethanol and lattice oxygen $\mathrm{O}_{O}^{X}$ in a metal oxide such as $\mathrm{ZnO}$ can be described in general by the following defect reaction (in Kröger-Vink notation):

$6 \mathrm{O}_{O}^{X}+\mathrm{C}_{2} \mathrm{H}_{5} \mathrm{OH}_{(\mathrm{g})} \rightarrow 2 \mathrm{CO}_{2(\mathrm{~g})}+3 \mathrm{H}_{2} \mathrm{O}_{(\mathrm{g})}+6 \mathrm{~V}^{\cdot}{ }_{\mathrm{O}}+12 \mathrm{e}^{-}$ 
Similarly, the interactions between ethanol and the surfaceadsorbed oxygen species ${ }^{27}$ such as superoxide ion $\mathrm{O}_{2}^{-}$and peroxide ion $\mathrm{O}_{2}^{2-}$ can be described as

$$
\begin{gathered}
3 \mathrm{O}_{2}^{-}+\mathrm{C}_{2} \mathrm{H}_{5} \mathrm{OH}_{(\mathrm{g})} \rightarrow 3 \mathrm{H}_{2} \mathrm{O}_{(\mathrm{g})}+2 \mathrm{CO}_{2(\mathrm{~g})}+3 \mathrm{e}^{-} \\
3 \mathrm{O}_{2}^{2-}+\mathrm{C}_{2} \mathrm{H}_{5} \mathrm{OH}_{(\mathrm{g})} \rightarrow 3 \mathrm{H}_{2} \mathrm{O}_{(\mathrm{g})}+2 \mathrm{CO}_{2(\mathrm{~g})}+6 \mathrm{e}^{-}
\end{gathered}
$$

These reactions produce more electrons and thus increase the conductivity of $\mathrm{ZnO}$ (n-type) upon exposure to ethanol. The dependence of conductivity on partial pressure of ethanol can be derived from these reactions using mass-action law and charge neutrality relations. It is noted, however, that these reactions are very general and schematic; ethanol molecules may dissociate to other intermediate species before oxidation at $\mathrm{ZnO}$ surfaces. However, identification of the intermediates requires some sensitive surface spectroscopic techniques and tremendous effort. Investigation into the detailed sensing mechanisms is still underway and will be reported subsequently.

\section{Conclusions}

Using a combustion CVD process, we have successfully synthesized a new two-dimensional structure, $\mathrm{ZnO}$ single crystal flakes. The flakes grew upward from the underneath $\mathrm{Si}$ substrate. The as-grown $\mathrm{ZnO}$ flakes were typically $200 \mathrm{~nm}$ thick and 10-20 $\mu \mathrm{m}$ wide. Unlike most 1-D $\mathrm{ZnO}$ structures with [0001] growth direction, $\mathrm{ZnO}$ flakes grow along $<10 \overline{1} 0>$ directions. Gas sensor based on a $200 \mathrm{~nm}$ thick $\mathrm{ZnO}$ flake exhibited high sensitivity and fast response to ethanol vapor.

\section{Acknowledgements}

This work was supported by the Office of Science, Department of Energy under Grant No. DE-FG0201ER15220, Department of Energy National Energy Technology Laboratory under Grant No. DE-FG2601NT41274, and by the Georgia Institute of Technology Molecular Design Institute under prime contract N00014-95-11116 from the Office of Naval Research.
Ying Liu, ${ }^{a}$ Jian Dong, ${ }^{a}$ Peter J. Hesketh ${ }^{b}$ and Meilin Liu* ${ }^{* a}$

${ }^{a}$ Center for Innovative Fuel Cell and Battery Technologies, School of Materials Science and Engineering, Georgia Institute of Technology, Atlanta, GA, 30332-0245, USA. E-mail: meilin.liu@mse.gatech.edu; Fax: 1404894 9140; Tel: 14048946114

${ }^{b}$ School of Mechanical Engineering, Georgia Institute of Technology, Atlanta, GA, 30332-0405, USA

\section{References}

1 T. Seiyama and A. Kato, Anal. Chem., 1962, 34, 1502.

2 H. W. Ryu, B. S. Park, S. A. Akbar, W. S. Lee, K. J. Hong, Y. J. Seo, D. C. Shin, J. S. Park and G. P. Choi, Sens. Actuators, B., 2003, 96, 717 .

3 D. F. Paraguay, M. Miki-Yoshida, J. Morales, J. Solis and L. W. Estrada, Thin Solid Films, 2000, 373, 137.

4 D. Gruber, F. Kraus and J. Müller, Sens. Actuators, B., 2003, 92, 81.

5 W. J. Moon, J. H. Yu and G. M. Choi, Sens. Actuators, B., 2002, 87, 464.

6 H. M. Lin, S. J. Tzeng, P. J. Hsiau and W. L. Tsai, Nanostruct. Mater., 1998, 10, 465

7 X. L. Cheng, H. Zhao, L. H. Huo, S. Gao and J. G. Zhao, Sens. Actuators, B., 2004, 102, 248.

8 C. Baratto, G. Sberveglieri, A. Onischuk, B. Caruso and S. di Stasio, Sens. Actuators, B., 2004, 100, 261.

9 H. Kind, H. Q. Yan, B. Messer, M. Law and P. D. Yang, Adv. Mater., 2002, 14, 158.

10 P. D. Yang, H. Q. Yan, S. Mao, R. Russo, J. Johnson, R. Saykally, N. Morris, J. Pham, R. R. He and H. J. Choi, Adv. Funct. Mater., 2002, 12, 323

11 S. C. Lyu, Y. Zhang, C. J. Lee, H. Ruh and H. J. Lee, Chem. Mater., 2003, 15, 3294.

12 Y. K. Tseng, C. J. Huang, H. M. Cheng, I. N. Lin, K. S. Liu and I. C. Chen, Adv. Funct. Mater., 2003, 13, 811.

13 Z. L. Wang, Mater. Today, 2004, 6, 26.

14 Y. Liu, S. Zha and M. Liu, Adv. Mater., 2004, 16, 256.

15 Y. Liu, W. Rauch, S. Zha and M. Liu, Solid State Ionics, 2004, 166, 261.

16 A. T. Hunt, W. B. Carter and J. K. Cochran, Appl. Phys. Lett., 1993, 63, 266.

17 Y. Liu, C. Compson and M. Liu, J. Power Sources, 2004, 138, 194.

18 J. Q. Hu, Q. Li, N. B. Wong, C. S. Lee and S. T. Lee, Chem. Mater., 2002, 14, 1216.

19 J. J. Wu and S. C. Liu, Adv. Mater., 2002, 14, 215.

20 P. X. Gao, Y. Ding and Z. L. Wang, Nano Lett., 2003, 3, 1315.

21 Z. W. Pan, Z. R. Dai and Z. L. Wang, Science, 2001, 291, 1947.

22 Y. Liu, J. Dong and M. Liu, Adv. Mater., 2004, 16, 353.

23 J. Y. Lao, J. Y. Huang, D. Z. Wang and Z. F. Ren, Nano Lett., 2003, 3, 235.

24 Z. L. Wang, J. Phys.: Condens. Matter, 2004, 16, R829.

25 M. Radecka, K. Zakrzewska and M. Rekas, Sens. Actuators, B., 1998, 47, 194

26 N. Barsan and U. Weimar, J. Electroceram., 2001, 7, 143.

27 D. Kohl, Sens. Actuators, B., 1989, 18, 71. 